\title{
VERISIMILITUDE AND THE SCIENTIFIC STRATEGY OF ECONOMIC THEORY
}

\author{
Jesús P. Zamora Bonilla \\ Journal of Economic Methodology. Vol. 6. 1999. Pp.: 331-350.
}

\begin{abstract}
Methodological norms in economic theorising are interpreted as rational strategies to optimise some epistemic utility functions. A definition of 'empirical verisimilitude' is defended as a plausible interpretation of the epistemic preferences of researchers. Some salient differences between the scientific strategies of physics and of economics are derived from the comparison of the relative costs associated to each strategy. The classical discussion about the 'realism of assumptions' in economics is also considered under the light of the concept of 'empirical verisimilitude'.
\end{abstract}

KEYWORDS. Economic-methodology; verisimilitude; realism; instrumentalism; rhetoric; economics-of-science. 


\section{METHODOLOGICAL NORMS AND EPISTEMIC UTILITIES.}

According to the growing economic approach to scientific research, scientists should be considered as rational agents pursuing a utility function under conditions of uncertainty, interdependence and limited resources. ${ }^{1}$ Science would so be seen as a more or less complex game, and its salient institutional features would be interpreted as 'equilibrium solutions' to that game. Furthermore, from the economist's point of view the exercise of understanding his own discipline with the help of his own analytical tools is an excellent opportunity to scrutinise the power of these tools and to become more self-conscious about his own practice. A big effort has been devoted in the past years to offer acceptable economic explanations of scientific institutions (though the task is still very far from completed), developing an interesting and stimulating alternative approach, or at least a complementary one, to that of sociology of science (either 'classical' -or 'Mertonian'- or 'radical' or -'deconstructionist'-); but very little has been done to understand from the economic-theoretical point of view such central scientific rules or 'institutions' that were the topic, not of sociology of science, but of methodology. I refer, obviously, to rules about theory choice and model building, about the value of experiments and observations as tests of those models and theories, about the relative importance of prediction, explanation and understanding, and so forth.

A plausible interpretation of these methodological norms is that they are simply conventional indications about the epistemic value of several alternatives, assuming that this notion of 'epistemic value' is an essential element of the scientists' utility functions. 
That is, we can assume that, ceteris paribus, a researcher will prefer that theory, model or set of data which has for him the highest possible epistemic value. Of course, different scientists may have different 'epistemic utility functions' (that is, a different epistemic element of their utility functions), but this does not preclude at all the possibility of explaining their different methodological preferences on the ground of their own epistemic values. It seems also plausible to see 'schools' within a single discipline, not only as groups defending similar theories, but mainly as sets of people sharing methodological and epistemic preferences different from the ones shared by other groups. On the other hand, since the researchers' utilities depend also on other kinds of things (prestige, income, credibility, power, practical uses of their discoveries), their individual choices can many times be inconsistent with the maximisation of epistemic values; but, if these values are seen as an essential goal of the collective enterprise of science, it seems reasonable to expect some kind of institutional enforcement of some methodological rules (for example, through formal education, review mechanisms, and so on). I will not pursue here an explanation of how this enforcement can be made effective, though I believe that this topic is one of the most exciting problems for the new economics of science.

The idea of an epistemic utility is not a new one in methodology of science ${ }^{2}$ it was proposed by Carl Hempel at the beginning of the 1960s, and developed by some followers of Rudolf Carnap's confirmationist approach and of the Bayesian explication of scientific reasoning; within these schools, the main epistemic utility associated to a scientific theory would be its truth, whose expected value is defined as the theory's degree of confirmation by the empirical evidence. From a different point of view, and following an idea of Karl Popper, several authors have also interpreted the idea of

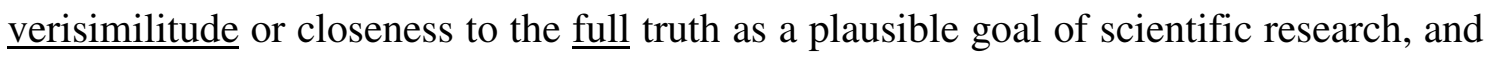


hence as a reasonable 'epistemic utility' for those who share a realist (rather than an instrumentalist or empiricist) interpretation of scientific knowledge. Some interesting work has been made both from the Bayesian approach and from the truthlikeness programme to show that some methodological norms usually followed (or, at least, preached) in scientific research can be derived from some definitions of those epistemic utilities; but nothing as ambitious as a 'complete' theory of the scientific method has been developed until now following these appealing lines.

I will examine in the following section some problems of the referred approaches, and will offer a different description of the epistemic goal of scientific research, a description somehow intermediate between empiricism and realism, and which, I think, captures better some essential elements of the epistemic preferences of real scientists. Of course, my aim in this paper is not to offer such a 'complete' account of the scientific method, nor of the method of economics, but simply to use my description of the epistemic utility function to illuminate a typical feature of economic theorising, namely, its habitual disdain for empirical testing (which I will try to explain in section III), as well as the classical discussion about the irrelevance of the 'realism of assumptions' (section IV).

\section{SOME EPISTEMIC UTILITIES.}

\section{Confirmationist approaches.}

Though the idea of epistemic utility has already been exploited in methodology,

its 'returns' have not been still very high. In the first place, the notion of degree of

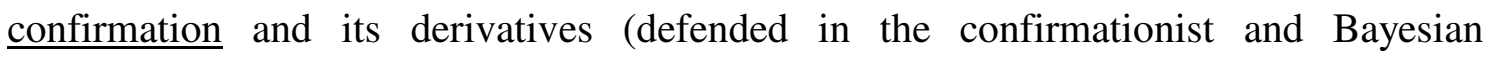


approaches ${ }^{3}$ ) suffer from a radical flaw when the empirical evidence contradicts the theory which is being evaluated. If we assume that the epistemic utility of scientific researchers is $\underline{\mathrm{p}(\mathrm{T}, \mathrm{E})}$, where $\underline{\mathrm{E}}$ is the empirical evidence and $\underline{\mathrm{T}}$ is a theory or hypothesis, then all refuted theories will have the minimum epistemic value. This contradicts the common idea that a series of refuted theories can show some epistemic progress: for example, we can rationally believe that Newton's theory of gravitation is better than the Keplerian model of the solar system, which is better than Copernicus', which is better than Ptolemy's; all these four theories have been contradicted by further empirical research, and so their degree of confirmation is simply zero, though some epistemic progress seems to exist in their temporal sequence. The situation is not better with another common 'epistemic utility', confirmation excess: $\underline{p(T, E)}-p(T)$. In this case, the value of an empirically refuted theory will be simply $\mathrm{p}(\mathrm{T})$; so, for example, Newton's theory will have less value than its conjunction with any independent statement, even if this is also false or absurd. If we take seriously the idea that all interesting scientific theories are false, either because they include idealisations or simplifications, or because they will have sooner or later some empirical anomalies, then the confirmationist and Bayesian approaches offer a poor indication about the real epistemic value of these theories.

\section{Verisimilitude.}

For the verisimilitude programme things are a little better. Since the logical refutation of Popper's original definitions of verisimilitude at the beginning of the 1970s, a large number of alternative definitions have been proposed. Two of the most appealing ones are those of Ilkka Niiniluoto and Theo Kuipers. The first has made a reasonable distinction between the actual closeness to the truth of a theory and the 
estimated value of this closeness under some empirical evidence. ${ }^{4}$ The former is an inverse function of the 'distances in the logical space' between the possible states of the world allowed by the theory and the actual state of the world; the latter is simply the statistical expectation to the first function. Though Niiniluoto's concepts allow to say that a refuted theory has a very high level of truthlikeness or expected truthlikeness, or is more verisimilar than another refuted theory, it suffers from two important problems: in the first place, according to his definitions, the verisimilitude of a theory will be essentially dependent on the language in which it is expressed; that is, if $\underline{\mathrm{t}(\mathrm{A})}$ and $\underline{\mathrm{t}(\mathrm{B})}$ are the translations of $\underline{\mathrm{A}}$ and $\underline{\mathrm{B}}$ to a different language, it can be the case that $\underline{\mathrm{A}}$ has more verisimilitude -either actual or expected- than $\underline{B}$, while $\underline{t(B)}$ is more truthlike than $\underline{t(A)}$. In the second place, his definition of estimated verisimilitude has not allowed thus far to derive interesting methodological rules, and so, it is of little use either to understand the actual development of science, or to give us indications about how to make theory choices which are efficient in the pursuit of truth.

Theo Kuipers has offered some semantic definitions of verisimilitude. ${ }^{5}$ According to the simplest one, a theory $\underline{\mathrm{A}}$ is closer to the truth than another theory $\underline{\mathrm{B}}$ if and only if all theoretically possible systems ('models' in the terminology of formal semantics, not in the economic sense) which make $\underline{B}$ true also make $\underline{A}$ true, and all theoretically possible systems incompatible with $\underline{\mathrm{A}}$ are also incompatible with $\underline{\mathrm{B}}$ (and there is some theoretically possible system compatible with $\underline{A}$ which is not compatible with $\underline{\mathrm{B}}$, or some impossible system compatible with $\underline{\mathrm{B}}$ and not compatible with $\underline{\mathrm{A}}$ ). Kuipers' idea is especially interesting because he replaces the notion of 'factual truth' for that of 'theoretical truth': the aim of scientific theories would not be to discover individual 'facts', but laws or regularities about the world. ${ }^{6}$ From this definition it is possible to prove that, if all known empirical laws derivable from $\underline{B}$ are also derivable 
from $\underline{\mathrm{A}}$ and there is some law derivable from $\underline{\mathrm{A}}$ which refutes $\underline{\mathrm{B}}$, then it is still possible that $\underline{\mathrm{A}}$ is closer to the truth than $\underline{\mathrm{B}}$, but it is not possible that $\underline{\mathrm{B}}$ is closer to the truth than $\underline{\mathrm{A}}$ (stated in more Popperian terms: the meta-hypothesis ' $\underline{\mathrm{A}}$ is closer to the truth than $\underline{\mathrm{B}}$ ' has been 'corroborated', in the sense that it has resisted the attempts to falsify it; the proof is based on the assumption that the set of all theoretically possible models is a subset of every confirmed empirical law, that is, on the assumption that these empirical laws are true). Hence, the hypothetico-deductive method would be consistent with the aim of getting theories which were closer and closer to the truth.

Unfortunately, it is also possible to prove that, in many interesting cases, comparisons of verisimilitude can not be made according to Kuipers' definition. For example, if $\underline{\mathrm{A}}$ and $\underline{\mathrm{B}}$ are mutually incompatible theories, and both have been empirically refuted (in the sense that all their models fail to obey at least one known empirical law), then the set of systems which make $\underline{A}$ true, the set of those which make $\underline{B}$ true, and the 'theoretical truth', will be pairwise disjoint, and neither $\underline{\mathrm{A}}$ nor $\underline{\mathrm{B}}$ can be closer to the truth than the other, whatever the relative number of successes of those theories. The same occurs if $\underline{\mathrm{A}}$ entails a law which is not entailed by $\underline{\mathrm{B}}$, and $\underline{\mathrm{B}}$ entails a law which is not entailed by $\underline{\mathrm{A}}$.

\section{Empirical verisimilitude.}

As we have seen, neither the confirmationist approach nor the verisimilitude programme seem to have supplied some 'epistemic utility' which is able to illuminate the actual course of science, or, at least, which is appropriate to be used as a normative criterion of epistemic rationality. I have proposed elsewhere to explore a different possibility, one in some way intermediate between realism and empiricism, and which I propose to call 'empirical verisimilitude'; ${ }^{7}$ according to this concept, the epistemic 
value of a theory depends essentially on two factors:

a) the similarity between the image of the world offered by the theory and the image of the world which derives from the known empirical regularities, and

b) the amount of information about the world that those regularities provide (which can be recursively defined as the empirical verisimilitude of the propositions stating those regularities, assessed through a still 'more empirical' set of statements).

This is a 'compromise' between empiricism and realism because, in the first place, the value of a theory is assessed basically through our empirical knowledge. But, on the other hand, a theory does not lose automatically its value if it is falsified, since a false theory can offer a description of the empirical facts more or less close to the true description of these facts. Moreover, this 'empirical knowledge' is simply constituted by the most verisimilar hypothesis about what in a certain process of research is taken as given, and this can refer to macroscopic, common-sense objects, or to highly 'theoretical' entities.

A possible formalisation of this idea is the following: let $\underline{T}$ be a theory or $\underline{\text { hypothesis, }}$, and let $\underline{\mathrm{E}}$ be a collection of empirical regularities about those aspects of the world that $\underline{\mathrm{T}}$ tries to explain (I will refer with $\underline{\mathrm{E}}$ sometimes to a set of statements, and other times to the conjunction of those statements); let $\underline{B}$ represent the 'background knowledge' or 'basic presuppositions' of a scientist or a scientific community, including metaphysical, heuristic or ontological principles, aesthetic preferences, moral or ideological principles, and so on; let $\mathrm{p}$ be a probability function, and, finally, let $\underline{\mathrm{X}^{\mathrm{u}}}$ represent the assertion that $\underline{X}$ is true under the margin of approximation $\mathrm{u}$. Hence, we can define: 
ii) $\underline{\operatorname{Inf}(X)}=1 / \underline{p(X, B)}$

iii) $\underline{\mathrm{Vs}_{1}} \underline{(T, E)}=\underline{\operatorname{Sim}(T, E) \operatorname{Inf}(E)}=\underline{p}(T, E \& B) / p(T v E, B)$

iv) $\underline{\mathrm{Vs}_{2}} \underline{(T, E, u, v)}=\underline{\mathrm{Vs}_{1}} \underline{\left(\mathrm{T}^{\mathrm{u}}, \mathrm{E}^{\mathrm{v}}\right)}$

v) $\underline{\mathrm{Vs}_{3}} \underline{(\mathrm{T}, \mathrm{E})}=\max (\underline{\mathrm{F}} \subseteq \underline{\mathrm{E}}) \underline{\mathrm{Vs}_{1}} \underline{(\mathrm{T}, \mathrm{F})}$

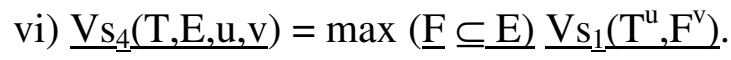

From these definitions it is possible to derive a set of methodological norms (in the sense explicated in section I) which are reasonable representations of some very common methodological attitudes. For example, with function $\underline{\mathrm{Vs}}_{1}$, the empirical verisimilitude of a theory increases if it is corroborated by a new empirical finding, if both its degree of confirmation and its likelihood increase, if a new fact is found such that it is more probable under $\underline{\mathrm{T} \& \mathrm{E}}$ than under $\underline{\mathrm{E}}$ alone, etc. Regarding the comparison of two theories, if both are confirmed by the empirical evidence, then the most informative (the less probable) will be the most verisimilar, but if both entail $\underline{\mathrm{E}}$, then the most probable will be the most verisimilar; when one of them is better confirmed than the other and is also less probable, then it will be more verisimilar; and if one of them has more likelihood and is more probable than the other, then it will also be more verisimilar. Another interesting consequence from the definition of $\underline{\mathrm{Vs}}_{1}$ is that the maximum empirical verisimilitude that $\underline{T}$ can receive (or $\underline{E}$ can give) is $\underline{\operatorname{Inf}(T)}$ (resp., $\underline{\operatorname{Inf}(E)})$, which forces to look for still less probable theories ('bold' ones, in Popper's terms) and for new informative empirical findings. Finally, the expected value of $\underline{\mathrm{Vs}_{1}}(\mathrm{~T}, \mathrm{E})$ is $\mathrm{p}(\mathrm{T} \& \mathrm{E}, \mathrm{B}) / \mathrm{p}(\mathrm{T}, \mathrm{B}) \mathrm{p}(\mathrm{E}, \mathrm{B})=\mathrm{p}(\mathrm{T}, \mathrm{E} \& \mathrm{~B}) / \mathrm{p}(\mathrm{T}, \mathrm{B})=\mathrm{p}(\mathrm{E}, \mathrm{T} \& \mathrm{~B}) / \mathrm{p}(\mathrm{E}, \mathrm{B})$, a typical Bayesian measure, which can be taken into account by scientists especially in those circumstances when new and unknown empirical results are expected. Unfortunately, 
$\underline{\mathrm{Vs}_{1}}$ has the same problem which invalidated the degree of confirmation as a measure of epistemic utility: it has the zero value for every refuted theory.

The other functions do not suffer from this problem. $\underline{\mathrm{Vs}_{2}}, \underline{\mathrm{Vs}_{3}} \underline{\underline{3}}$ and $\underline{\mathrm{Vs}_{4}} \underline{4}_{4}$ exploit the idea that the similarity between $\underline{\mathrm{E}}$ and $\underline{\mathrm{T}}$ depends basically on the similarity between the different states of the world consistent with each proposition, and on the relation

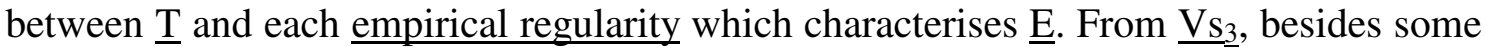
of the results commented above (sometimes more or less reformulated), it is also possible to derive the following fundamental theorem:

(2) Suppose that all the empirical facts in $\underline{E}$ are statistically independent of each other, and that the only possible connections between each one and $\underline{T}$ are the following: either it is entailed by $\underline{\mathrm{T}}$, or its negation is entailed by $\underline{\mathrm{T}}$, or it is statistically independent of $\underline{T}$ (and the same for $\underline{S}$ ). Under this assumption, if $\underline{T}$ entails all the empirical facts in $\underline{E}$ entailed by $\underline{S}, \underline{S}$ is refuted by all the empirical facts that refute $\underline{T}$, and $\underline{p(S, B)} \leq \underline{p(T, B)}$, then $\underline{\mathrm{VS}_{3}} \underline{(\mathrm{S}, \mathrm{E})} \leq \underline{\mathrm{VS}_{3}} \underline{(\mathrm{T}, \mathrm{E})}$.

The proof is based on a lemma which asserts that, given the idealising assumptions expressed in the first part of the theorem, then the value of $\underline{\mathrm{VS}_{3}} \underline{(T, E)}$ is

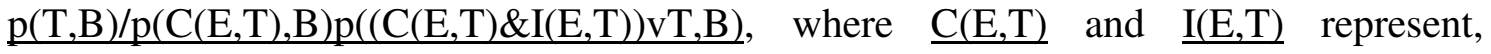
respectively, those regularities in $\underline{\mathrm{E}}$ which are explained by $\underline{\mathrm{T}}$ and those which are statistically independent of $\underline{\mathrm{T}}$.

Assuming that $\underline{\mathrm{p}(\mathrm{T}, \mathrm{B})}$ is 'small' with respect to both $\underline{\mathrm{p}(\mathrm{C}(\mathrm{E}, \mathrm{T}), \mathrm{B})}$ and $\mathrm{p}(\mathrm{I}(\mathrm{E}, \mathrm{T}), \mathrm{B})$ (that is, if universal theories are always much less probable a priori than any conjunction of empirical regularities), then $\underline{\mathrm{Vs}_{3}} \underline{(\mathrm{T}, \mathrm{E})}$ and $\underline{\mathrm{Vs}}_{4} \underline{(\mathrm{T}, \mathrm{E})}$ can be approximated respectively by: 


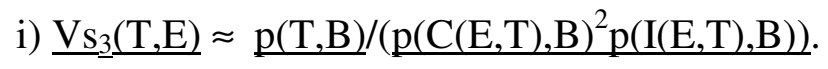

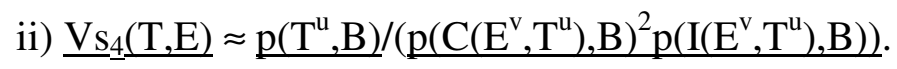

We can interpret the denominator of these expressions as indicating that, though it is good for a theory both to explain the empirical facts and not to be falsified by them, the former is still better than the latter.

Theorem (2) allows to understand a common methodological attitude among scientists, one that is difficult to explain from other formal reconstructions of the scientific method. It is the fact that a higher empirical success is not a sufficient condition for preferring one theory to another; that is, a theory may have proved its superiority in terms of the amount of facts explained by it and of its resistance to falsification, but many scientists may still prefer an 'empirically inferior' theory, even

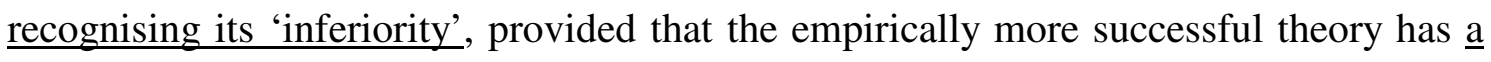
very low prior probability in comparison with the less successful one. Since 'revolutionary' theories usually contain hypotheses which are contrary to the background presuppositions of the 'old' scientific community, they can be rejected by many researchers even if these theories explain successfully many of the 'anomalies of the old paradigm' (to use Thomas Kuhn's classic terms). This means that, if $\underline{\mathrm{Vs}_{3}}$ (or some close epistemic utility function) represent correctly the 'institutional' methodological preferences of scientists, these will search for theories which are not only empirically successful, but also 'plausible' or 'realistic' from their metaphysic, ontological or heuristic points of view. This reinforces my interpretation of those functions as measures of 'empirical verisimilitude', and not only as measures of empirical support. 
On the other hand, if the empirical data are accumulating at a high rate, it is possible to substitute in $\underline{\mathrm{VS}_{3}}$ the occurrence of $\underline{\mathrm{Vs}_{1}}$ for its expected value (that is, $\underline{\Sigma(\mathrm{x} \in \mathrm{F}) \mathrm{Vs}_{1}}(\underline{\mathrm{T}}, \mathrm{x}) \mathrm{p}(\mathrm{x}, \mathrm{F})$, where the $\underline{\mathrm{x}}$ 's are the minimal points into which the logical space can be divided). If we call $\underline{\mathrm{V}_{\underline{5}}}$ the resulting measure, it is possible to prove that, under the assumptions of theorem (2), $\underline{\mathrm{Vs}_{5}} \underline{\underline{T}, \mathrm{E})}=\underline{1 / \mathrm{p}(\mathrm{C}(\mathrm{T}, \mathrm{E}), \mathrm{B})}$. Hence, if a theory explains at least all the facts explained by another (i. e., if $\underline{\mathrm{C}(\mathrm{T}, \mathrm{E})}$ includes $\underline{\mathrm{C}(\mathrm{S}, \mathrm{E})})$, then the former will seem at least as close to the truth as the latter, independently of the cases where they are falsified, and independently of their prior probability. This seems to be consistent with Lakatos' indication that, during the first stages of a scientific research programme (when the number of new empirical findings is growing at a high rate), falsifications are not taken into account, only confirmations.

\section{IS ECONOMIC THEORY TOO THEORETICAL?}

The general methodological norms derivable from measures $\underline{\mathrm{VS}_{3}} \underline{\underline{ }}$ and $\underline{\mathrm{Vs}_{5}} \underline{5}$ are, from my point of view, close enough to the common ideas about the nature of scientific method as to allow us to take them as more or less acceptable (though strongly simplified and idealised) descriptions of the epistemic element in the scientists' utility functions. This does not imply that all scientists have the same epistemic utility function, since the values of our Vs's will depend on each researcher's subjective probabilities and background presuppositions. But, if my hypothesis is true, scientists will look for theories which 1) are 'highly plausible' according to their background presuppositions, 2) have many and important empirical successes, and 3) have few empirical failures. Note especially that the second requirement usually goes against the 
first one: in order to explain many and strong empirical laws, a theory must be logically strong, and hence, it will have a low prior probability. This fact is not a contradiction, but an essential trade-off in scientific theorising. It simply means that finding out a highly verisimilar theory is not an easy task, since one need look for simple, realistic and elegant principles with one eye, and for strong empirical predictions with the other.

The idea I am going to defend in this section is that we can employ these utility functions to show that methodological differences among scientific disciplines can exist because the relative costs of each methodological decision are different in each discipline.

Scientific researchers are human subjects who must choose one single option in every situation they confront; they must choose what lines of research to pursue, what problems to tackle, which known techniques to apply, which new ones to learn, what empirical observations or experiments to make, and so on. Obviously, each individual researcher will tend to take that decision which gives to him a higher level of 'utility', though it is reasonable to expect that, from the 'institutional' point of view, the best decision, and so, the one which will tend to be socially sanctioned, will be that which produces a higher 'epistemic value' (if this is not so, we can think of a 'failure' of the corresponding institution). In any case, all those decisions will have different expected 'returns' (both for the individual and for his scientific community) depending on the peculiarities of the objects under study in each discipline, on the theoretical, observational and experimental techniques available, and also on the different background presuppositions of each scientific community. This means that, even if two disciplines share the same epistemic utility function, each one will tend to use a different combination of methods as long as they confront different relative costs. 
For the sake of simplicity, imagine that a scientist has only two possible 'instruments' to choose between them: theoretical refinements and empirical testing, to which some amount of effort can be devoted in continuous quantities $\underline{\mathrm{TR}}$ and $\underline{\mathrm{ET}}$. Some differences between two disciplines (say, economics and physics) can be explained because of the different rates of return associated to each combination of these instruments. I will refer here to theoretical economics and theoretical physics, that is, to the work of those researchers whose explicit aim is to find out a 'theory' about a certain aspect of the world $;^{8}$ I will also assume that these researchers try to find out a theory which has the highest possible value of ${\underline{V_{s}}}_{\underline{3}}$ or ${\underline{V_{s}}}_{4}$. The horizontal axis of fig. 1 indicates the amount of effort devoted to the empirical testing of the devised theories, that is, to the attempt to derive testable empirical consequences from them and to indicate the empirical data which could be used to test them; if these attempts are successful, they will make it to increase the denominator of the expression of $\underline{\mathrm{Vs}_{3}}$ (as approximated in (3)). The vertical axis represents the amount of effort devoted to theoretical refinements, that is, to attempts to make the theory more plausible, i. e., more consistent with the discipline's background presuppositions; this will make it to increase the value of the numerator of $\underline{\mathrm{VS}_{3}}$. For each combination of $\underline{\mathrm{ET}}$ and $\underline{\mathrm{TR}}$ there will be a certain expected level of verisimilitude associated to it. It is reasonable to assume that the curves of constant expected verisimilitude must be decreasing (since a lesser amount of effort devoted to one instrument has to be compensated with a higher effort devoted to the other one) and convex (indicating decreasing marginal returns of each instrument: equal increments in the use of one instrument allow to substitute decreasing amounts of the effort devoted to the other one). Fig. 1 also shows that, at any point of the ET-TR space, the iso-expected verisimilitude curve of physics passing through that point will have a steeper slope than the curve corresponding to economics; 
this is due to the fact that an equivalent decrease of effort devoted to theoretical refinement will be easier to compensate in physics with some additional effort devoted to testing than in economics (that is, in general it is less costly to devise strong and successful empirical tests in the former than in the latter, while we can suppose that successful theoretical refinements have more or less the same cost in each discipline; of course, the expected level of verisimilitude associated to one point of the ET-TR space needs not be the same in both disciplines: it is reasonable to suppose that it is higher in physics than in economics). ${ }^{9}$

Figure 1

Assuming that the same total amount of effort can be expended by a physicist and an economist, both will have the same 'budget constraint' (a straight line with slope equal to -1 ), and their optimal choices will be those represented in fig. 2, where $\underline{\text { T }^{\mathrm{e}}}$, $\underline{\mathrm{TR}^{\mathrm{e}}}, \underline{\mathrm{ET}^{\mathrm{p}}}$ and $\underline{\mathrm{TR}^{\mathrm{p}}}$ are respectively the amounts of effort in each scientific instrument chosen by economists and by physicists. The obvious conclusion is that the theoretical economist will devote more effort to theoretical refinements than the theoretical physicist, and less effort to empirical testing. It is important to note that the same utility function is assumed both to represent the epistemic preferences of physicists and those of economists; so, this methodological difference is due, according to the argument, only to the difference in the relative costs of empirical testing in both disciplines. 
Figure 2

This can be taken as a peculiar defence of the position usually known as 'physics envy': the reason why economists have particular methodological practices is not that their epistemic preferences are essentially different from those of natural scientists; they simply confront a different set of constraints in their research processes. Economists try to discover and explain true, permanent, meaningful and objective facts about the world, just like any other natural or social scientist, but this does not entail that they should imitate the others' strategies. Economists, simply, are doing the best they can in the maximisation of verisimilitude with the instruments they have and the kind of stuff they confront. Then, if the relative costs of empirical and theoretical (successful) research in economics and in physics are as I have supposed, then the hypothesis that both disciplines attempt to maximise the value of $\underline{\mathrm{Vs}_{3}} \underline{\underline{3}}$ or $\underline{\mathrm{Vs}_{4}}$ not only explains the acceptance of several methodological rules of theory choice, but also some differences in the methodological patterns which we can observe in those sciences.

So, coming back to the question with which this section begun ('is economic theory too theoretical?'), from the fact that economic theory is more theoretical and less empirical than theoretical physics, it does not follow necessarily that it is also too theoretical and too little influenced by empirical testing. It would not make it necessarily 'better' with some different combination of theory and testing, since this choice would lead to a lesser expected verisimilitude than that reached through the optimal choice in fig. 2. Given the nature of economic facts, transferring to empirical testing some part of the effort devoted to theoretical refinements would not warrant that economic theories become better from the epistemic point of view. ${ }^{10}$ 


\section{REALISM AND VERISIMILITUDE IN ECONOMICS.}

Milton Friedman's classical prescription of devoting much effort to finding out successful predictions, and much less to justifying the 'realism' (or, as it has been suggested by Uskali Mäki, the 'realisticness') of the economic models' assumptions, seems to be particularly conflicting with the conclusion of the past section. ${ }^{11}$ I have interpreted the search for successful predictions as an attempt to maximise the value of the denominator of $\underline{\mathrm{Vs}}_{3}$ or $\underline{\mathrm{Vs}}_{4}$ for some given theory, and we can read Friedman's recommendation as telling that what economists should do would be to choose the 'right corner solution' in fig. 2, or some point close to it. But, if the 'epistemic returns' of each strategy are as depicted in fig. 1, it will be more efficient for the maximisation of $\underline{\mathrm{Vs}_{\underline{3}}}$ or $\underline{\mathrm{Vs}}_{4}$ to follow some 'mixed' strategy, even some one more skewed towards the left corner. This means that, besides some reasonable degree of empirical success, economic theories will normally tend to be defended on the ground of their consistency and similarity with the background presuppositions of the discipline (or of each economic school), and this is a highly theoretical work. ${ }^{12}$

The numerators of $\underline{\mathrm{Vs}_{3}} \underline{\underline{\mathrm{Vs}_{4}}}$ in (3) were, respectively, $\underline{\mathrm{p}(\mathrm{T}, \mathrm{B})}$ and $\underline{\mathrm{p}\left(\mathrm{T}^{\mathrm{u}}, \mathrm{B}\right)}$. Maximising these quantities can be reasonably interpreted as maximising the degree of realisticness of the theory, not in the (Popperian) sense of its 'closeness to the full -and unknown- truth', but in the less obscure sense of its coherence with our basic beliefs about the working of the economic system and about the desirable formal structure of economic models (recall that $\underline{B}$ comprises not only ontological but also ideological and heuristic assumptions). The second expression $\left(\underline{\mathrm{p}\left(\mathrm{T}^{\mathrm{u}}, \mathrm{B}\right)}\right)$ takes also into account that, 
though theory $\underline{\mathrm{T}}$ may be surely false according to our background presuppositions (because it contains simplifications, idealisations, or other counterfactual assumptions) it can nevertheless offer a description of reality similar to what one basically assumes about the world, and the prior probability of $\underline{T}^{\mathrm{u}}$ can be high even if the margin of approximation $\underline{\mathrm{u}}$ is more or less small. So, even a very formalised and stylised economic model can still be very 'plausible' for many economists if its assumptions are consistent with three basic ideas: the identification of individual rationality with expected utility maximisation, the assumption that a stable equilibrium obtains, and the idea that certain mathematical concepts and techniques offer a description of the economic situation not very far from the way things essentially are. The elements of reality which are more contradictory with the idealised structure of the model are usually considered 'less relevant', in such a way that their suppression in the model is not seen as a big departure from reality. For example, the assumptions of price-taker agents and one-price in competitive markets, of rational expectations in new classical macroeconomics, or of more or less ad hoc utility functions in the economics of information, all of these are seen as unacceptably strong idealisations by many heterodox economists, but simply as approximately true descriptions of the world by many mainstream scholars. This means that the underlying definition of the margins of approximation $\underline{u}$ will be basically school-dependent, and we can take it as an essential element of the 'basic presuppositions' of each school (that is, as an element of $\underline{\mathrm{B}})^{13}$

It is interesting to note that one of Friedman's main arguments to defend the acceptability of the maximisation hypothesis is that the market will eliminate, through a process of 'natural selection', those entrepreneurs who do not choose that strategy which leads them to make maximum profits; so, we can expect that the market will be populated mainly by profit-maximising firms, even if their managers do not consciously 
intend to make optimum profits. But no empirical proof of this argument is offered in Friedman's essay. So, the value of this argument depends solely on its consistency with our basic knowledge of the functioning of the market. Stated in our formal framework, Friedman's aim is to show that, even if our background ideas (ㅌ) are in contradiction with the hypothesis 'entrepreneurs try to make maximum profits' $(\underline{\mathrm{H}})$, the probability of the proposition 'entrepreneurs act as if they tried to maximise profits' $\left(\underline{\mathrm{H}^{\mathrm{u}}}\right)$ given $\underline{\mathrm{B}}$ is, instead, very high.

The consistency between the empirical consequences of a theory and our observations of reality are, of course, another important element to assess the epistemic value of that theory. In fact, it can also be argued that a theory is said to be 'realistic' if, among other things, it makes correct predictions ${ }^{14}$. For, if two theories have the same degree of prior probability, but one of them makes much better predictions than the other, then the former will obviously offer a description of the known facts 'closer to the truth' than the latter. The expression of $\underline{\mathrm{Vs}_{4}}$ also takes into account that, in order to reach a high epistemic value, it is not strictly necessary to have a full coincidence between the theory's predictions and the empirical observations: the theory can simply make predictions which are close enough to the observed facts ( $\underline{\mathrm{v}}$ being the acceptable margin of approximation). But, in any case, if the effort directed towards the discovery of successful predictions is less productive in economics in terms of verisimilitude than the elaboration of elegant models and mathematical proofs, it is reasonable to expect that theoretical economists will devote less effort to that kind of activity than other scientists.

The fact that increasing $\underline{\mathrm{p}(\mathrm{T}, \mathrm{B})}$ or $\underline{\mathrm{p}\left(\mathrm{T}^{\mathrm{u}}, \mathrm{B}\right)}$ is a good strategy for the maximisation of the verisimilitude of $\underline{\mathrm{T}}$, has contributed to create the impression that economic theory is a deductive science (rather than an 'inductive' or 'hypothetico- 
deductive' one). This is due to the fact that the best way of increasing the prior probability of $\underline{\mathrm{T}}$ is simply to show that it derives from $\underline{\mathrm{B}}$ (since, in this case, $\underline{\mathrm{p}(\mathrm{T}, \mathrm{B})}$ equals one). If the main postulates of economic theory derive from common sense, from casual experience or from a priori judgements (as it was defended by most prominent economists in the Classical School and by some others in the present), then no amount of empirical testing would be necessary. But in that case economic theory would offer simply a conceptualisation of empirical facts, not an explanation of them. For example, one can try to transform economic hypotheses into formal theorems, as Adam Smith's 'invisible hand' and Walras' 'general equilibrium' ideas where transformed into Arrow's and Debreu's proof of the first fundamental theorem of welfare economics. In a case like this, we would have the left corner solution in fig. 2 . This extreme solution is also a too extreme one. Perhaps Friedman was thinking of such 'apriorist' approaches to economics when he proclaimed the necessity of more empirical testing, though he exaggerated in saying that this testing alone were the only source of epistemic value for economic theories and models.

Finally I shall indicate some connections between my conclusions and several recent approaches to economic methodology. In the first place, the difference between the strategies of maximising the denominator or the numerator of the expressions in (3) is similar to the difference indicated by Uskali Mäki between 'empirical' and 'ontological' constraints on economic theorising ${ }^{15}$. Economic theories must be 'realistic' in the sense of employing assumptions as close as possible to what we know about the working of the economy, as well as in the sense of offering detailed descriptions of some 'hidden' structure of the economic system (note that what is 'hidden' are the connections between economic facts, not some kind of 'theoretical' economic entities). Obviously, the acceptability of the hypotheses about such 'hidden' 
structure must be also assessed mainly by their empirical success. Furthermore, both in physics and in economics, once a theory about some 'unobserved' reality has reached a satisfactory level of empirical verisimilitude, it can be taken as a 'datum' to be explained by a still 'deeper' theory. Unfortunately for the economics profession, physicists have been more successful in finding out such verisimilar theories at different levels of 'depth'.

Uskali Mäki has been also one of the few economic methodologists who have tried to make an interesting use of the concept of verisimilitude. In a short contribution to a book on falsificationism in economics ${ }^{16}$, he has attempted 'to outline an idea of how an economist with essentialist intuitions might view scientific progress as increasing truthlikeness'. His idea (which he calls 'essesimilitude') is basically that of maximising "likeness or closeness to the truth about essences or ontic cores in the economy' ${ }^{17}$, where these 'cores' are seen as deeper and deeper 'layers' of the real systems under study. I guess that my definitions of empirical verisimilitude offer an acceptable formal reconstruction of some of the intuitions behind Mäki's proposal, since they can be interpreted as 'the degree in which a theory seems to have approximately captured the essential elements of a given reality'. These 'essential elements' are, simply, what our basic presuppositions tell us a priori about the economic system plus what our experience has shown a posteriori as strong regularities about that system (and, the stronger they are, the more 'essential'); obviously, a theory can only have a high value of $\underline{\mathrm{VS}_{3}}$ or $\underline{\mathrm{Vs}}_{4}$ by being highly compatible with those presuppositions and by entailing many known regularities as strong as possible (remember that this last requisite tends to favour theories which are 'deeper', and hence, less probable a priori). Finally, note also that, as in the case of Kuipers' definition of verisimilitude, my own definitions do not refer to the closeness of a theory to the actual state of the world, but 
to its closeness to a set of lawlike propositions (some of them discovered by means of reflection and some others empirically).

In the second place, and regarding the work of Deirdre McCloskey, ${ }^{18}$ the approach followed in this paper allows to give a definite sense to the expression 'rhetoric', and hence, to see 'persuasion' as a rational strategy in the maximisation of verisimilitude. I propose to include under the term 'rhetoric' all those arguments directed towards the modification of prior probabilities; since the probability functions employed in this paper have been assumed to be subjective, they can be changed through the use of many kinds of strategies. For example, if you did not know that $\underline{T}$ can be derived from $\underline{B}$, but accept a proof of such a derivation later, your subjective value of $\mathrm{p}(\mathrm{T}, \mathrm{B})$ will pass from some number lesser than one to one; this proof can be a formal one (like the transformation of the 'invisible hand' hypothesis into the first fundamental theorem of welfare economics), or an informal one (like Alchian's and Friedman's 'proof' that the market will tend to select the profit maximasing firms). In other cases, a mere change of wording can serve sometimes to shift downwards or upwards someone's subjective prior probabilities; think, for example, of the refrasing of 'natural rate of unemployment' into 'non accelerating inflation rate of unemployment', or of 'profit' into 'surplus'. As long as all these strategies can make it higher or lower the value of $\underline{\mathrm{p}(\mathrm{T}, \mathrm{B})}$, they can be used to affect the verisimilitude that each researcher assigns to theory $\underline{\mathrm{T}}$. In this sense, rhetoric should not be seen as a strategy opposite to that of increasing the realisticness of economic models, but rather as a very useful way to do just this, as Mäki has recently suggested. ${ }^{19}$

Lastly, my criticism to instrumentalist methodology in economics has also some interesting connections with Hausman's diagnosis of the economic method. According to Hausman, mainstream economic theory has been governed since the times of the 
classics by the strategies of 'inexactness', which he accepts, and 'separateness', which he criticises. ${ }^{20}$ As I understand these strategies (which I will not try to interpret in depth here), the former amounts to the recognition that economic reality is too complicated to be described in detail by tractable economic theories; so, these theories will necessarily offer inexact (and sometimes very inexact) descriptions of the facts. The strategy of separateness amounts to the refusal to explore alternative causal hypotheses, different from the 'individualist-rationality-with-equilibrium' assumption of most economic models. Hausman suggests ${ }^{21}$ that, though inexactness can not be totally avoided, some of its negative consequences could by alleviated through the use of richer empirical methods; from the point of view of the model I have developed in section III, the use of new empirical methods would make the iso-expected verisimilitude curves of economics more sloped, moving towards the right the optimal choice in fig. 2, and, on the other hand, it would increase the height of each curve, and accordingly the maximum expected verisimilitude reachable with a given amount of effort. With respect to separateness, Hausman's recommendation is to explore new theoretical possibilities; this would be equivalent to putting under scrutiny the background presuppositions of economic schools, especially of mainstream economics. In any case, both of Hausman suggestions would be something like an 'external shock' in the model of section III, and so, it is difficult to see how the economics profession could undertake 'endogenously' such a revolutionary change in its tools and its basic presuppositions. 


\section{CONCLUSION.}

In spite of its increasing mathematical sophistication, economic theory is a branch of science much different from physics; the main source of this difference is not the impossibility of building up economic models in an axiomatic fashion, nor the supposed fact that the epistemic aims of economics are not the same as those of physics. I have assumed in this paper that all science has the same fundamental epistemic aim: maximisation of empirical verisimilitude, which basically depends on the prior plausibility of each theory and of its degree of empirical success. From this asumption I have shown that methodological differences between scientific disciplines can be explained by the different 'rates of return' that each methodological strategy may have in each discipline. In particular, it is rational to expect that economic theory is less empirical than those branches of natural science where succesful strong predictions are easier to make. This means that increasing the plausibility of the economic models' assumptions (i. e., increasing their 'realisticness') will usually be a reasonable strategy for the maximisation of the verisimilitude of economic theories. Rhetoric, for example, can be taken as an instrument, among others, to carry out this strategy, and not as something running against the pursuit of 'realisticness'.

\section{NOTES}

\footnotetext{
* Research for this paper has been funded by the Spanish Government's DGICYT, as part of research project PB 95-0125-C06 ('Science and Values'). I want to thank prof.
} 
Javier Echeverría for giving me the opportunity of taking part in that project. Two preliminary versions were presented at the Seminar 'Realism and Rationality in Economics', Madrid, C.S.I.C., Instituto de Filosofía, May 1998 and at the meeting on Daniel Hausman's Philosophy of Economics organised by Wenceslao González at Ferrol, Universidade da Coruña, March 1999. I am thankful to Francisco Alvarez, Juan Carlos García-Bermejo, Daniel Hausman and Juan Urrutia, as well as to two anonymous referees, for helpful comments and criticisms, and especially to Uskali Mäki for his patience revising my text. All remaining shortcomings are exclusively my fault. My ideas on realism have also benefited from a longstanding discussion with José Antonio Díez, José Luis Falguera, Andoni Ibarra and Ulises Moulines.

${ }^{1}$ Two brief summaries of the key issues in the field are Dasgupta and David (1994) and Stephan (1996). A longer survey of the main problems is Wible (1998). From a more philosophical perspective, see also Kitcher (1993, ch. 8). Some 'classic' attempts to model scientific decisions in an economic fashion are Peirce (1879), Boland (1971), Sneed (1989) and Goldman and Shaked (1991).

${ }^{2}$ See Niiniluoto (1987, ch. 12) for a survey of the concept's history.

${ }^{3}$ One of the most complete and convincing expositions is Howson and Urbach (1989).

${ }^{4}$ See esp. Niiniluoto (1987). For a survey of the recent work on verisimilitude, see Niiniluoto (1998).

${ }^{5}$ See, for example, Kuipers (1992) and (1996).

${ }^{6}$ Of course, the notion of 'theoretical possibility' is far from being clearly definable, but I will not discuss it here.

${ }^{7}$ See Zamora Bonilla (1996) and (1997).

${ }^{8}$ Most economists throughout the world are not theoretical economists, that is, they do not have the aim of devising and establishing theories or abstract models; they simply 
try to apply some tools derived from economic theory or from statistics to explain, understand or predict economic facts, or to make some economic prescriptions (I owe this observation to Uskali Mäki). Of course, the work of these 'empirical economists' is the main source of facts to be used in the testing of theories and models, but this is not the 'effort' I am referring to when I talk about 'empirical testing'; by this expression I mean the work of deriving testable predictions and indicating the data which could be relevant for that testing.

${ }^{9}$ One anonymous referee indicated that empirical testing is actually not cheaper in physics than in economics: many experiments, especially in high-energy physics, are incredibly expensive, indeed! Besides the fact that most experiments in physics are not so expensive, one can also argue that the 'total' cost of an experiment is not an appropriate measure; what is important is the 'unit' cost of an increase in $1 / \mathrm{p}(\mathrm{C}(\mathrm{E}, \mathrm{T}))$ : one can reasonable doubt that one million dollars spent on economic experiments or observations may produce the same amount of strong empirical regularities than the same money devoted to physical or chemical experiments. On the other hand, what I am analysing is the choice of the theoretical scientists, who must choose between increasing his theory's verisimilitude by 'polishing' it formally and conceptually, and doing it by deriving predictions from it; the cost (in money units) of testing these predictions will not affect his choice as long as this cost is assumed by the experimenters; the theoretician's costs I am referring to are, instead, 'psychic' costs (such as effort and time).

In any case, I think we can make the prediction that, as the cost of experimentation in certain branches of natural sciences rise disproportionately, the ratio of 'theoretical refinements' to 'empirical research' will also grow in them. 
${ }^{10}$ Economic theory would be too theoretical if its practitioners chose an amount of effort in theoretical refinements still higher than $\underline{\mathrm{TR}^{\mathrm{e}}}$. Obviously, if we take into account not only the epistemic part of the economists' utility functions, it is certainly possible that they face a system of incentives which tend to overestimate theoretical work, but this should be interpreted as a failure of the institutional mechanisms which sanction the 'right' methodological attitudes of the theoretical economists' profession (see Mayer (1993) for a convincing argument in favour of the existence of this failure). I will not discuss here whether such perverse incentives exist or not; my point is simply that being less empirical than physics or other natural sciences is not a sufficient reason to assert that economic theory is too theoretical.

${ }^{11}$ Friedman (1953).

${ }^{12}$ We can also read Friedman's thesis as defending that iso-expected verisimilitude lines in fig. 1 are vertical; these lines would represent the epistemic utility function of a typical instrumentalist. But the consistency of the methodological rules derivable from $\underline{\mathrm{VS}_{3}}$ and $\underline{\mathrm{Vs}}_{4}$ with some common methodological attitudes indicates, from my point of view, that real scientific researchers (including economists) are actually not so instrumentalist at all.

${ }^{13}$ Take also into account that these margins can not usually be defined quantitatively and precisely, but only in a very qualitative and informal fashion.

${ }^{14}$ This is, for example, one of the senses of 'realisticness' examined in Mäki (1994), p. 242. I am using the term 'prediction' to cover whatever empirically testable consequence of an economic theory or model, not necessarily one directed towards the future.

${ }^{15}$ See Mäki (forthcoming), whose ideas have strongly influenced this paper.

16 Mäki (1991). 
${ }^{17}$ Op. cit., p. 89.

${ }^{18}$ See McCloskey (1985).

${ }^{19}$ See Mäki (1995). On the other hand, I think that rhetoric may still have another important role within economic theorising (and within scientific theorising in general), which is related to the fact that the verisimilitude of a theory depends essentially upon the basic presuppositions (' $\underline{B}$ ') of each 'school'. This role would be to help us in the discussion about which presuppositions are more reasonable. For example, we could discuss whether the acceptability of an economic model should depend more on the realisticness of its assumptions than on its mathematical elegance, whether the existence of a general equilibrium should be taken for granted in macroeconomic models or not, whether politicians should be described as mere 'rent maximisers' in order to understand the influence of the government into the economy, and so on. I think that, in general, the arguments supporting one position or another in those discussions have to be 'rhetoric', in the sense that they are lastly grounded neither on logical proofs nor on empirical data.

${ }^{20}$ See Hausman (1992), pp. 90 ff.

${ }^{21}$ Hausman (1992), pp. 253-4.

\section{REFERENCES}

Boland, L. (1971) 'Methodology as an Exercise in Economic Analysis', Philosophy of Science, 38:105-17.

Dasgupta, P. and P. A. David (1994) 'Toward a New Economics of Science', Research Policy, 23: 487-521. 
Goldman, A. and M. Shaked (1991) 'An Economic Model of Scientific Activity and Truth Acquisition', Philosophical Studies, 63: 31-55.

Hausman, D. M. (1992) The Inexact and Separate Science of Economics, Cambridge, Cambridge University Press.

Friedman, M. (1953) 'The Methodology of Positive Economics', in Essays in Positive Economics, Chicago, University of Chicago Press, pp. 3-43.

Howson, C. and P. Urbach (1989) Scientific Reasoning. The Bayesian Approach., La Salle (Ill.), Open Court.

Kitcher, P. (1993) The Advancement of Science, Oxford, Oxford University Press.

Kuipers, T. A. F. (1992) 'Naive and Refined Truth Approximation', Synthese, 93, 299-341.

Kuipers, T. A. F. (1996). 'Truth Approximation by the Hypothetico-Deductive Method', in W. Balzer and C. U. Moulines, Structuralist Theory of Science. Focal Issues,

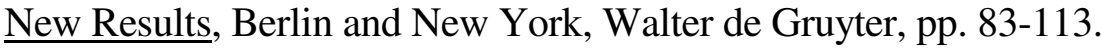

McCloskey, D. (1985) The Rhetoric of Economics, Madison, University of Wisconsin Press.

Mäki, U. (1991) 'Comment' (to D. W. Hands 'The Problem of Excess Content: Economics, Novelty and a Long Popperian Tale'), in N. de Marchi and M. Blaug (eds.), Appraising Economic Theories. Studies in the Methodology of Research Programs, Hants (U.K), Edward Elgar, pp. 85-90.

Mäki, U. (1994) 'Reorienting the Assumptions Issue', in R. E. Backhouse (ed.), New Directions in Economic Methodology, London, Routledge, pp. 236-256.

Mäki, U. (1995) 'Diagnosing McCloskey', Journal of Economic Literature, 33: $1300-1318$. 
Mäki, U. (forthcoming) 'The Way the World Works (www): Towards an Ontology of Theory Choice", in U. Mäki (ed.), The Economic Realm: Studies in the Ontology of Economics.

Mayer, T. (1993) Truth versus Precision in Economics, Hants (U.K.), Edward Elgar.

Niiniluoto, I. (1987) Truthlikeness, Dordrecht, D. Reidel.

Niiniluoto, I. (1998) 'Verisimilitude: The Third Period', British Journal for the Philosophy of Science, 49: 1-29.

Peirce, Ch. S. (1879) 'A Note on the Theory of the Economy of Research', reprinted in Journal of Economic Methodology (1994), 1: 314-329.

Sneed, J. D. (1989) 'Micro-Economic Models of Problem Choice in Basic Science', Erkenntnis, 30: 207-24.

Stephan, P. E. (1996) 'The Economics of Science', Journal of Economic Literature, 34: 1199-1235.

Wible, J. R. (1998) The Economics of Science. Methodology and Epistemology as if Economics Really Mattered, London, Routledge.

Zamora Bonilla, J. P. (1996) 'Verisimilitude, Structuralism and Scientific Progress', Erkenntnis, 44: 25-47.

Zamora Bonilla, J. P. (1997) ‘An Invitation to Methodonomics’, in A. Ibarra and T. Mormann (eds.), Representations of Scientific Rationality: Contemporary Formal Philosophy of Science in Spain, Poznan Studies in the Philosophy of Science 61: 233251. 
Department of Economics. Universidad Carlos III

28903 Getafe. Madrid. Spain

e-mail: jpzb@eco.uc3m.es

7 April 1999

8,488 words 